\title{
NIF Power Conditioning System Testing at LLNL
}

E. S. Fulkerson, M. Newton, S. Hulsey, J. Hammon, W. B. S. Moore

This article was submitted to

Pulse Power Plasma Science 2001 Conference Las Vegas, NV

June 17-22, 2001

\section{June 5, 2001}

U.S. Department of Energy

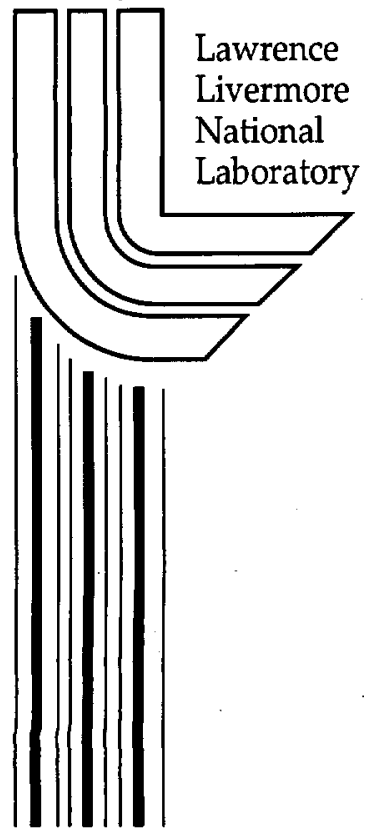

Approved for public release; further dissemination unlimited 


\section{DISCLAIMER}

This document was prepared as an account of work sponsored by an agency of the United States Government. Neither the United States Government nor the University of California nor any of their employees, makes any warranty, express or implied, or assumes any legal liability or responsibility for the accuracy, completeness, or usefulness of any information, apparatus, product, or process disclosed, or represents that its use would not infringe privately owned rights. Reference herein to any specific commercial product, process, or service by trade name, trademark, manufacturer, or otherwise, does not necessarily constitute or imply its endorsement, recommendation, or favoring by the United States Government or the University of California. The views and opinions of authors expressed herein do not necessarily state or reflect those of the United States Government or the University of California, and shall not be used for advertising or product endorsement purposes.

This is a preprint of a paper intended for publication in a journal or proceedings. Since changes may be made before publication, this preprint is made available with the understanding that it will not be cited or reproduced without the permission of the author.

This report has been reproduced

directly from the best available copy.

Available to DOE and DOE contractors from the

Office of Scientific and Technical Information

P.O. Box 62, Oak Ridge, TN 37831

Prices available from (423) 576-8401

http://apollo.osti.gov/bridge/

Available to the public from the

National Technical Information Service

U.S. Department of Commerce

5285 Port Royal Rd.,

Springfield, VA 22161

http://www.ntis.gov/

OR

Lawrence Livermore National Laboratory

Technical Information Department's Digital Library

http://www.llnl.gov/tid/Library.html 


\title{
NIF Power Conditioning System Testing at LLNL ${ }^{*}$
}

\author{
E. Stephen Fulkerson \\ Mark Newton \\ Scott Hulsey \\ Lawrence Livermore National laboratory \\ Jud Hammon \\ Titan Corporation, Pulse Sciences Division ${ }^{* *}$ \\ William B. S. Moore \\ Sandia National Laboratories
}

\section{Introduction}

The National Ignition Facility (NIF) is now under construction at the Lawrence Livermore National Laboratory (LLNL). The Power Conditioning System (PCS) for NIF, when completed will consist of a 192 nearly identical 2 megajoule capacitor storage banks driving 7680 two meter long flashlamps. A fully integrated single-module test facility was completed in August of 2000 at LLNL. The purpose to the Test Facility is to conduct Reliability and Maintainability (RAM) testing of a true "First Article" system (built to the final drawing package as opposed to a prototype). The test facility can be fired once every ten minutes with a total peak output current of $580 \mathrm{kA}$ with a pulse width of $400 \mathrm{us}$. To date over 4000 full power "shots" have been conducted at this facility.

\section{Facility}

The system consists of the computer control and data acquisition sub-system, a Pre-Ionization Lamp Check (PILC) pulser, a Main Energy Storage Module (MESM), twenty high voltage transmission cables, and a standard NIF flashlamp load.

Each "channel" of the Power Conditioning System has two sources that supply current to the flashlamps. The main 2MJ bank and the PILC; a smaller unit used for Pre-Ionizing the flashlamps (to ensure more uniform performance) and as a Lamp Check system to determine the condition of the flashlamps before and after a system shot. The PILC pulser basically consists of a $130 \mu \mathrm{F}(60 \mathrm{~kJ})$ capacitor bank with sparkgap output switch and it's associated triggering circuitry.

Presently the control system uses the same LabView based, Windows NT PC that was used on the FANTM prototype system at Sandia National Laboratory, Albuquerque N.M ${ }^{i}$. This will be replaced with the actual NIF hardware and software as testing continues.

The MESM can contain up to 24 (20 nominal) $300 \mathrm{uF}$ energy storage capacitors. The nominal energy storage of the MESM is approximately $1.7 \mathrm{MJ}$, at the maximum designed operating voltage of $24 \mathrm{kV}$. With a full load out of 24 capacitors, the MESM can store up to $2.2 \mathrm{MJ}$. The capacitors are effectively in parallel. A stainless steel inductive/resistive $(9 \mu \mathrm{H} / 0.026 \mathrm{ohms})$ damping element in series with each capacitor limits fault currents in the event of a capacitor or main bus failure. During prototype testing there were several failures resulting in the release of considerable pressure and high-speed projectiles. The room containing the MESM therefore has a "maze" vent system to release pressure while containing debris in the event of an uncontrolled energy release. The walls are armored with $1 \frac{1}{2}$-inch plywood.

A single spark gap switches the entire bank output through ballast inductors to the set of twenty output cables. Each transmission cable has it own ballast inductor to insure current sharing. The values of the

\footnotetext{
* This work was performed under the auspices of the U.S. Department of Energy by the Lawrence Livermore National Laboratory under contract No. W-7405-Eng-48

${ }^{* *}$ The Titan Corporation acquired the pulsed power portion of Maxwell Physics International Company in March, 2001

*** Presently at on assignment at Lawrence Livermore National Laboratories, Livermore, CA
} 
inductors are varied with cable length. The cable length chosen for the initial testing was 180 feet. This represents the longest cable run (worst case for performance) in the NIF system.

The flashlamp load consists of an actual NIF Frame Assembly Unit or FAU. The FAU holds 20 series pairs of flashlamps and is located in it's own room adjacent to the MESM unit.

\section{The Test Program}

The primary purpose of the testing program is to develop reliability and maintainability data to provide confidence in the design. Procedures for producing, activating and integrating the full 192-module system are also being developed. To date over 4,000 full systems shots have been conducted on the system. The first 402 shots where conducted with a mix of prototype and production pulse power hardware. In December, the MESM was upgraded to full production status.

Short Circuit Testing: When a Main Energy Storage Module is first activated, the initial testing is done into a short circuit instead of a full flashlamp load. In this way the MESM can be tested at full rated current while operating at lower voltage and stored energies. The transmission cables are replaced with a 4-gauge wire connected from the output side of each ballast inductor directly back to pulse power ground. Full rated output current (approximately $29 \mathrm{kA}$ for each of the twenty outputs) can be achieved at only $9 \mathrm{kV}$ and less than $400 \mathrm{~kJ}$ stored energy. This allows the module

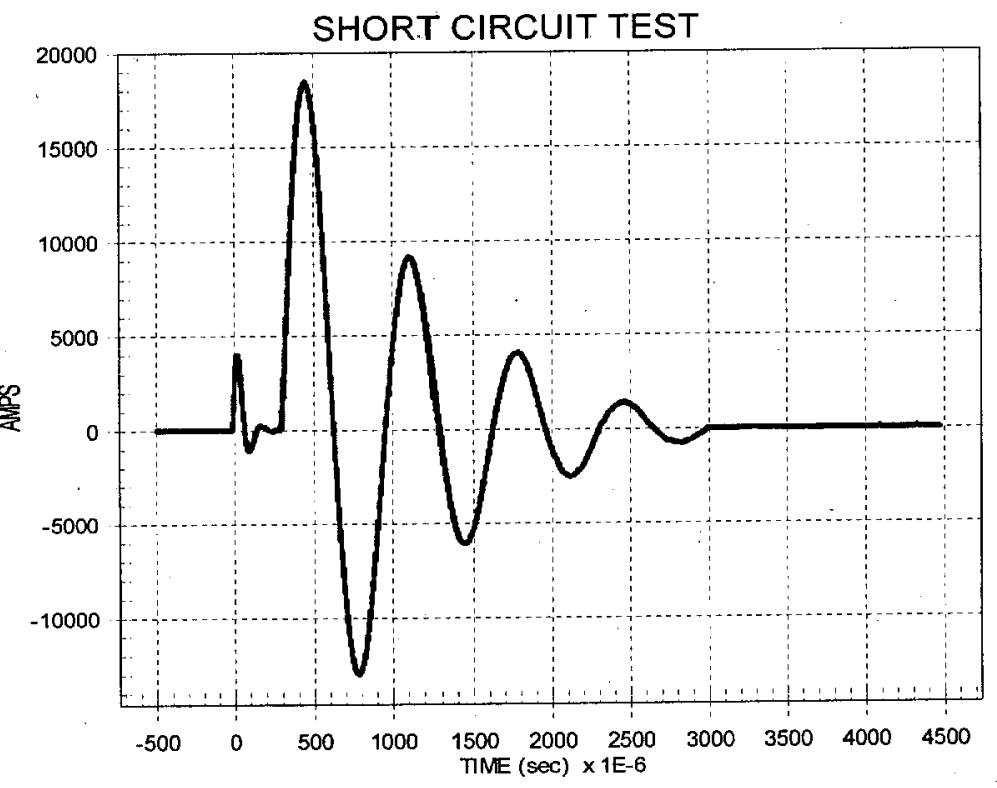
to be operated safely with the main doors removed (the $400 \mathrm{~kJ}$ figure limits the energy that can be imparted to any projectiles in case of a failure). Video cameras are positioned to observe any high current arcs caused by loose connections. Each test is video taped and it is a relatively simple process to identify and correct the source of any such arcing. Calibration of the current sensors is also conducted at this time. An external current probe is positioned at each short circuit and each of the 20 internal sensors is compared to the calibrated external probe. This is also the method by which the production modules will be tested at the factory before shipment to LLNL.

A side effect of the short circuit testing was a chance to refine the circuit modeling. Because the system is underdamped in this mode, the module current "rings". This allows for easy determination of the overall inductance and resistance of the module, with out the complicating non-linear effects of the flashlamps. Inductance is calculated from the period of ringing compared with the known capacitance of the bank. The resistance is found from the rate of decay of the ringing current waveform.

Testing into a Flashlamp Load: After the completion of the short circuit testing, the output cables and the main doors are attached. The module is brought up to full voltage $(24 \mathrm{kV})$ to test the high voltage integrity and the bank safety dump resistors. The MESM has a redundant dump system so each pair of dump resistors must be tested in turn. The dumps are tested at the end of each day's operation. 
Before the main bank is discharged into the flashlamps, firing the PILC pulser alone tests the integrity of the cables and flashlamps. In the waveform at right the PILC signal is seen as the smaller (4kA) signal $300 \mu$ before the main current pulse. Video cameras are again used to observe for arcing. Once it has been established that the connections to the flashlamps are secure, several low voltage main bank shots are taken, each at a higher voltage until normal operating voltage is reached. One of the effects of the pre-

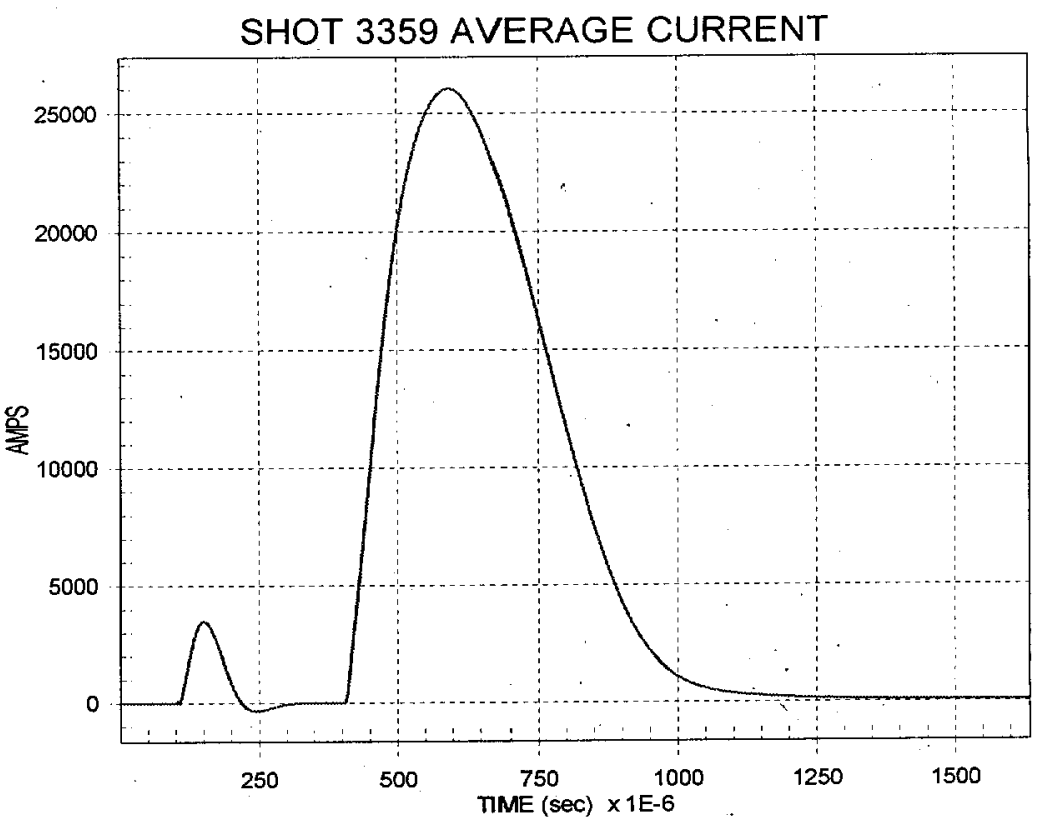
ionization signal is to allow the flashlamps to breakdown at a lower voltage during the main current pulse. If the PILC pulser is fired along with the main switch, then the main bank can be operated at quite low voltages $(<5 \mathrm{kV})$. A typical current waveform for a single flashlamp pair is shown above.

A serious Laser Bay contamination concern has been the issue of eddy-current induced arcing in the Frame Assembly Units that contain the flashlamps. Previous non-NIF like flashlamp load enclosures have exhibited significant arcing. The sources of these arcs are points in the enclosure that only make "casual contact", such as the main door or side panels. The NIF design has been careful to eliminate any such poor mating surfaces. Over the course of testing the FAU has been opened several times and thoroughly inspected, no signs of eddy-current arcing have been detected.

The pattern for testing is to operate the pulser until the main switch timing jitter starts to increase, indicating that the main gap has reached its "end of life" dimension of 0.85 " (approximately 1800 shots $/ 283,000$ total Coulombs transferred). At this point the main switch is removed and replaced with a newly reconditioned unit. To provide additional reliability data for the capacitor charging power supplies, a new supply also installed at this point.

Transportation Test: The production plan calls for the MESM, Main Trigger unit, PILC Pulser and Control System to be tested and calibrated into a short circuit at the vendors' site. The sub-units will be "unmated" at the factory then trucked, assembled, to the NIF site. At this point they will be "re-married". Moving the assembled MESM was considered "high risk" without a demonstration. In early April 2001, the system was shut down and prepared for the transportation test. The MESM was placed on a flat bed truck and sent on a "road trip" of 8 hours, over a mix of highway types. The system was reactivated without incident.

Ground System Tests: The facility has also been used to validate the design of the NIF safety grounding system. In the event of a high voltage/current failure, the system must limit the "touch potential" exposure of personnel and equipment to safe levels. The system was configured to simulate various possible failure conditions. A low voltage/high current (40V/400A) external pulser was used to inject scaled fault currents. Measurements were made of current paths and induced voltages, and compared to simulations and other ground system test data. The data collected confirmed the NIF design will limit touch potentials to safe levels in the event of a fault. Details of the design and testing are presented in "Safety Grounding Approach for the National Ignition Facility Power Conditioning System,"ii. 
Gain Coefficient Verification:

The Power Conditioning System must deliver sufficient energy to the FAU flashlamps such that the laser glass gain coefficient meets requirements. This parameter is expressed as a percent gain in laser light per centimeter of glass. There are two basic points that must be met; a baseline gain of $5.0 \% / \mathrm{cm}$ with 20 capacitors/module and a growth position of $5.2 \% / \mathrm{cm}$ with a full load out of 24 capacitors.

Laser gain and flashlamp drive measurements made on the prototype NIF amplifier (AMPLAB). have been used to create a computer code (GainCalc) that predicts laser gain based on the power delivered to the flashlamp load by the PCS modules. The NIF MESM test facility, as constructed, represents a worse-than-worst-case scenario. The resistance of the transmission cables represents a significant source of losses in the system; the 180-foot cable length installed represents the longest cable run in the NIF system. The value of ballast inductor is selected to compensate for the inductance of the transmission cables - long cables use lower values of inductance than short units. The present ballast inductors are units that are sized for the shortest NIF cable run ( $66 \mathrm{ft}$ ); considerably higher inductance (and resistance) than will actually be used with the $180 \mathrm{ft}$ cables lengths installed in the test facility. Furthermore, the capacitance of the bank is on the low side of the expected average value. The gain code predicts that under the "worse-case" conditions being tested in the facility the predicted gain coefficient will be $5.26 \%$

\section{Lessons Learned}

During the course of testing several design problems have come to light; main bank capacitor charging powers supplies were failing and the main switch trigger unit output voltage was lower than predicted. Analysis of test facility operating data and some additional testing on the facility have led to solutions to these issues.

Relocation of Power Supply Charging Point: Originally the main capacitor charging power supply was connected through 40 ohms directly to the Main bus of the MESM. The $\mathrm{di} / \mathrm{dt}$ rate $\left(5 \mathrm{X} 10^{9} \mathrm{~A} / \mathrm{sec}\right)$ of the MESM at shot time combined with the inductances of the Damping Elements subjected the supply a very large $(17 \mathrm{kV})$ ringing voltage transient. This is believed to have lead to the failures of two power supplies. By relocating the charging point to junction of a single capacitor/damping element pair, this transition has been reduced to a mild $600 \mathrm{~V}$ step with no ringing (see plot right). No power supplies have failed since this modification.

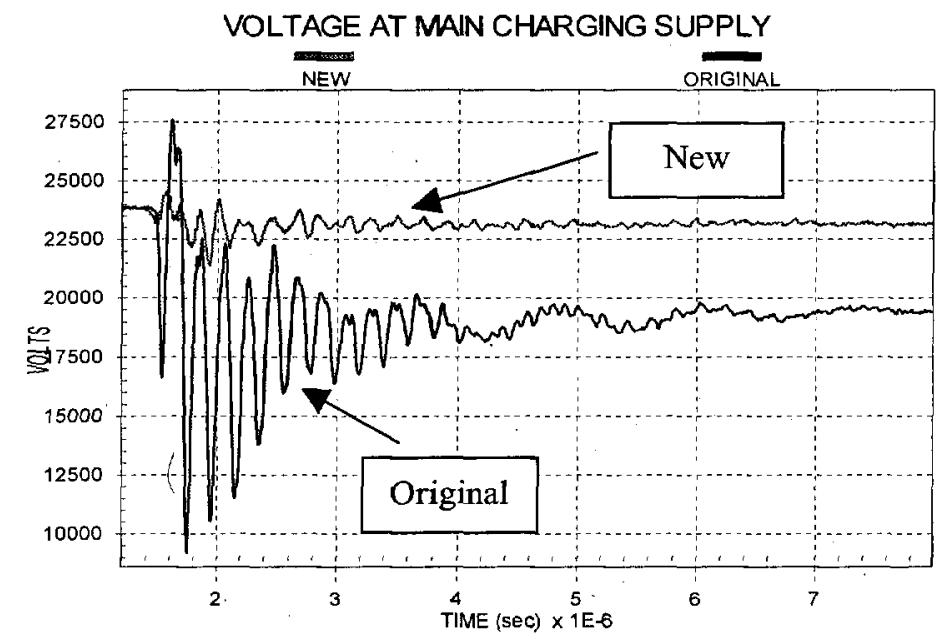


TG-803 Main Trigger Modifications: Analysis of early LLNL test data, combined with data from the FANTM prototype module, revealed an interaction between the PILC pulser and the TG-803 Main Trigger unit. It was discovered that the PILC signal caused the UV pre-illumination gap in the TG-803 to fire prematurely. This resulted in a decrease in voltage output from the trigger unit and increased trigger jitter. The output circuit of the trigger unit was modified to prevent this interaction resulting in a $35 \%$ increase in trigger voltage and an attendant increase in main switch life.

Originally the output peaking switch used in the TG- 803 was a pressurized air unit. Over many shots, it was noted that the time at which the switch triggered was increasing. If this was allowed to continue, a point could be reached at which the switch would no longer fire. The gas fill in the switch was changed to nitrogen, and the problem has been eliminated.

\section{Future Testing}

As mentioned earlier the present control system dates back to the FANTM prototype system. The production Control System hardware/software is scheduled for introduction and testing in June 2001. Each MESM in the PCS system switches out over 500kA on each system shot. The potential for interference with other NIF systems is an area of concern. Preliminary EMI/RFI measurements have been taken with further tests scheduled for this spring/summer. Currently the PILC pulser is supplied by a one of a kind power supply from the FANTM prototype. A series of vendor power supply qualification tests will begin this fall.

\section{Conclusion}

Over 4,000 full systems shots have been conducted on the system. The system meets performance goals for predicted gain coefficient. Several design problems have been identified and corrected. To demonstrate the reliability required for NIF, a goal of ten thousand shots (a NIF lifetime) by $010 C T 2001$ has been established, with a follow on 10,000 shots in fiscal 2002 .

\footnotetext{
${ }^{i}$ D.L.Smith, J.Hammon, J.M.Wilson, H.C.Harjes, and W.B.S.Moore, "FANTM: First Article NIF Test Module", IEEE Transactions on Plasma Science, Special Issue on Pulsed Power Science \& Technology Volume 28, Number 5, Pages 1316-1323 (October 2000)

ii J. Hammon, E.S. Fulkerson "Safety Grounding Approach for the National Ignition Facility Power Conditioning System”, Pulse Power Plasma Science PPPS-2001 conference, June 17-22, 2001 Las Vegas, Nevada, USA.
} 


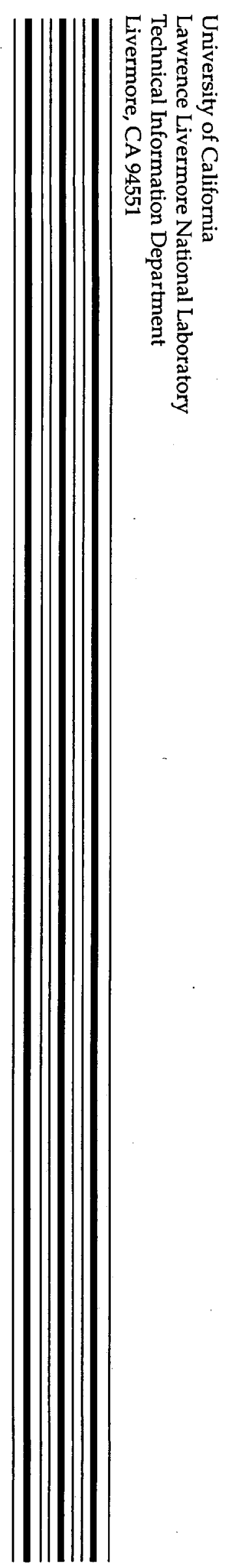

